\title{
CARACTERIZACIÓNFENOTÍPICADEL GENOFONDO AVÍCOLA CRIOLLO DE SAN ANDRÉS, PINAR DEL RÍO, CUBA
}

\author{
PHENOTYPIC CHARACTERIZATION OF CREOLE POULTRY GENETIC BASIS FROM \\ SAN ANDRÉS, PINAR DEL RÍO, CUBA
}

\author{
Valdés Corrales, R.J. ${ }^{1}$, Pimentel, O. ${ }^{1}$, Martínez, K. ${ }^{1}$ y Ferro, E.M. ${ }^{1}$
}

${ }^{1}$ Facultad de Agronomía de Montaña San Andrés.Universidad de Pinar del Río. Cuba.

Palabras clave adicionales

Plumaje. Color.

\section{RESUMEN}

El objetivo de este trabajo fue estimar por el método de observación la frecuencia de aparición de algunos rasgos de apariencia fenotípica de la gallina Criolla (Gallus gallus) en tres zonas del valle San Andrés del municipio La Palma, en la provincia de Pinar del Río, para aportar a la caracterización fenotípica de este genofondo avícola criollo. Como resultado se identificaron 28 caracteres agrupados en 8 rasgos de apariencia fenotípica (color del plumaje, tipo de plumaje, tipo de cresta color de los tarsos, presencia de patas plumosas, color de la piel, color del pico y color de las orejuelas). Los resultados de este trabajo han orientado el desarrollo de otras investigaciones con el propósito de evaluar la adaptabilidad y productividad de este genofondo avícola y su posible asociación con los rasgos de apariencia fenotípica encontrados.

\section{SUMMARY}

The objective of this work was to estimate by observation methods, the appearance's frequency of some phenotypic features in Creole hen (Gallus gallus) in three regions of San Andrés, province of Pinar del Río, in order to contribute at phenotypic characterization of creole poultry's genetic basis. As a result were identified 28 characters contained in 8 phenotypic features (plumage's color, plumage's type, crest's type, paws's color, presence of feathery paws, skin's color, color of the pick and color of ears). The results of this work have guided the development of other investigations with the purpose of evaluating the adaptability and

Recibido: 20-2-07. Aceptado: 6-3-07.
ADDITIONAL KEYWORDS

Plumage. Colour.

productivity of the poultry's genetic basis and their possible association with the phenotypic features founded.

\section{INTRODUCCIÓN}

En Cuba se trabaja en la búsqueda de alternativas de producción avícola, entre ellas las de ampliar los sistemas de cría extensivos. Por esto resulta necesaria la búsqueda de genotipos de aves adecuados para estas condiciones donde se necesitan aves de una mayor rusticidad, capaces de adaptarse a la crianza al aire libre.

La raza Criolla está distribuida en zonas campesinas de Cuba. Se origina en las aves traídas durante la época colonial y el posterior mestizaje con las introducidas, caracterizándose por su resistencia al clima, adaptación a la explotación de traspatio y rendimiento productivo (Pérez, 1993).

La identificación, el monitoreo y la conservación de los caracteres puede ayudar a reducir los peligros inherentes de los programas de crianza y salvaguardar la diversidad genética de las aves (Goudja, 1994). El estudio de la frecuencia de aparición de los diferentes rasgos posibilitará el establecimiento de patrones de correlación con caracteres productivos y reproductivos que garanticen un progreso genético en periodos de tiempo corto.

Arch. Zootec. 59 (228): 597-600. 2010. 


\section{VALDÉS CORRALES, PIMENTEL, MARTÍNEZY FERRO}

\section{MATERIAL Y MÉTODOS}

El estudio se realizó en tres áreas: Puesto Escondido (1), Infernal (2) y Ceja del Río (3), donde se desarrolla la crianza de aves de traspatio de la estirpe criolla, caracterizando 1990 animales adultos (1680 gallinas y 310 gallos), en el periodo 2003-2005 en los cuales se registraron el color y tipo de plumaje, tipo de cresta, color de los tarsos, presencia de patas plumosas, color de la piel, pico y orejuelas. El examen visual fue la técnica empleada. Los resultados que arrojó el estudio se ordenaron por rasgo fenotípico para calcular sus frecuencias por sexo y el total por grupo.

Para realizar el análisis estadístico se ejecutó una comparación de proporciones, mediante la prueba de Chi-cuadrado, con el programa del Instituto Nacional de Ciencias Agrícolas (INCA), comparándose los rasgos antes citados.

\section{RESULTADOSYDISCUSIÓN}

La agrupación por rasgos de los caracteres fue: color del plumaje (negro, rojo, negro-rojo, giro, barrado, gris, blanco, amarillo); tipo de pluma (normal, cuello desnudo, rizado); tipo de cresta (sencilla, guisante, rosa, nuez); color de los tarsos (amarillo, negro, blanco); patas plumosas (si, no); color de la piel (amarilla, blanca); color del pico (negra, amarillo, blanco); color de la orejuela (rojo, blanco).

\section{FRECUENCIA DE APARICIÓNDE LOSRASGOS YSUS CARACTERES FENOTIIPICOS \\ Color del plumaje: Se definen 8 caracte- res: plumaje (negro, rojo, negro-rojo, giro, barrado, gris, blanco y amarillo). En el grupo 1 (machos), aparecen tres características con igual frecuencia, plumaje negro, rojo y barrado (22\%) y los caracteres plumaje ne- gro y rojo, giro y barrado el $11 \%$. En el caso de las hembras, se registró el plumaje negro $(24,2 \%)$, barrado $(22,4 \%)$ y amarillo $(19 \%)$ y el gris con solo $1,7 \%$. \\ Caracteres predominantes del grupo:}

plumaje negro $(23 \%)$, barrado $(22 \%)$ y amarillo (16\%) y gris $(2 \%)$, en los machos (grupo 2) el plumaje barrado fue el más representado $(36 \%)$ y el menos el giro (9\%). Para las hembras, plumaje negro (36\%) y $4 \%$, gris. En conclusión, los caracteres predominantes en el grupo son: plumaje negro (33\%), barrado (19\%) y amarillo (15\%) y el gris es el menos frecuente (3\%). En el grupo 3, los machos presentan plumaje barrado (33\%) o gris (8\%). En las hembras: plumaje negro (26\%), negro y rojo (25\%); blanco es el menos representado. Resumiendo, para el grupo 3, los caracteres dominantes son: plumaje negro $(25 \%)$, negro y rojo $(22 \%)$ y giro $(15 \%)$ siendo el gris y blanco (3\%) los menos representados. Las aves con plumajes oscuros acumulan el 75\% de la muestra, resultados similares han sido reportados en México por Espinosa (1991) y sostienen que los plumajes oscuros las hacen menos visibles a los depredadores.

En el tipo de plumaje del grupo 1, los machos solamente lo poseen normal y el $4 \%$ de las hembras lo mostró rizado. Estos resultados implican que en este grupo aparece con plumaje normal un $89 \%$ del total. En el grupo 2, el $82 \%$ de los machos muestra plumaje normal y cuello desnudo el $18 \%$. En las hembras el normal supone el $84 \%$ y el rizado $2 \%$.

Realizando el análisis del tipo de plumaje que poseen los animales en el área, se observa que, en los machos, el carácter más común es el normal ( $88 \%)$, representando el cuello rizado sólo el 3\%. La frecuencia de aparición del tipo normal, fue de un $88 \%$ lo que permite asumir la dominancia de este carácter.

Otro rasgo estudiado fue el tipo de cresta, en el grupo 1, el 44\% de los machos la tenían sencilla siendo menos representado el tipo en rosa ( $11 \%$ de los animales), en las hembras el $59 \%$ posee cresta sencilla y el $7 \%$ aparece en nuez. Por ello, de los animales muestreados en el grupo, el 56\% tienen cresta sencilla y el 9\% la tienen en nuez.

Para los machos del grupo 2 no ocurre 


\section{GENOFONDO CRIOLLO EN SAN ANDRÉS}

igual, ya que el carácter dominante es el de cresta sencilla $(82 \%)$ y la cresta en rosa es el menos frecuente (18\%). En las hembras el $82 \%$ posee cresta sencilla y el resto en guisante.

En toda la zona los resultados son: cresta sencilla $(82 \%)$, en rosa $(11 \%)$, en nuez $(5 \%)$ y en guisante $(2 \%)$. Varios trabajos asocian la cresta en rosa con una baja fertilidad, especialmente en los machos en estado homocigótico (RR), atribuible a un decremento en la viabilidad espermática en comparación con los otros fenotipos (Kirby etal., 1998).

Otras características morfológicas: el color preponderante del tarso del grupo 1, tanto para machos como hembras es amari$110(61 \%)$ y el blanco es el menos representado $(8 \%)$. En tanto, para ambos sexos el tipo de patas predominante es sin plumas (94\%) y el color de la piel el blanco (73\%) o amarillo (27\%). En cuanto al color del pico de ambos sexos, el 78\% de los machos es amarillo y negro en el $54 \%$ de las hembras. Resumiendo el $49 \%$ negro, el $43 \%$ amarillo y el $8 \%$ blanco. En los machos el $78 \%$ poseía orejuelas de color rojo; en las hembras el $50 \%$ rojas y el $50 \%$ blancas, en general en este grupo el $54 \%$ tienen orejuelas rojas y $46 \%$ blancas.

En el grupo 2, los machos presentan el tarso amarillo y negro (46\%), en las hembras el predominante es el blanco (46\%) y amari11 o $(12 \%)$. En cuanto al tipo de patas, para ambos sexos el carácter preponderante es el de patas sin plumas y solo el $2 \%$ de los animales las tienen plumosas.

El color de la piel dominante en ambos sexos es blanco $(81 \%)$. El color amarillo en el pico en ambos sexos es el carácter más frecuente $(52 \%)$. En cuanto el color de las orejuelas, para el total predomina el rojo $(67 \%)$ y blanco $(33 \%)$. Los colores amarillo y blanco del tarso, predominan en los machos del grupo 3, mientras que en las hembras es más frecuente el blanco $(46 \%)$ y el amarillo (12\%). Al analizar el tipo de patas, se encontró que en general el carácter domi- nante es el de patas sin plumas $(99 \%)$. El color de la piel que prevalece, es el blanco $(81 \%)$, en tanto que el color de pico amarillo, es el más frecuente $(52 \%)$. El color de las orejuelas, que con más frecuencia apareció, fue el rojo $(67 \%)$.

Al analizar el color de los tarsos, el color amarillo es más frecuente (47\%) y mediante una prueba de hipótesis se demostró que el color del plumaje es independiente del color de los tarsos $(p<0,05)$. En cuanto al tipo de patas para ambos sexos el carácter predominante es el de patas sin plumas.

La frecuencia para tarsos emplumados fue baja e indica la procedencia asiática de la raza (Pérez, 1993). Para el color de la piel, la mayoría exhibe piel blanca. El carácter pico amarillo y color negro en todos, fueron los más frecuentes. Tanto para los machos como para las hembras, el carácter dominante es el color rojo, con el $34 \%$ blancas.

En el análisis estadístico se realizó una comparación de proporciones, mediante la prueba de Chi-cuadrado, contrastándose el color de la pluma, tipo de pluma, tipo de cresta, color del tarso, patas plumosas, color de la piel, del pico y de las orejuelas. En el análisis de proporciones para el color del plumaje, se comprobó que los colores identificados, tienen diferencias entre ellos.

Al realizar la prueba de Duncan, resultó que para el color del plumaje, el negro es el que mayor diferencia marcaba. El barrado y negro-rojo también marcan diferencias, resultando los plumajes oscuros los predominantes en todos los grupos, al comparar los colores del plumaje, advertimos que el gris es el menos representado. En cuanto al tipo de plumaje, el carácter normal es más frecuente para los tres grupos y el cuello desnudo y rizado están menos representados.

La cresta sencilla fue el carácter que más sobresalió, así como la cresta en rosa que también se manifiesta entre los animales estudiados. La menor representación la tienen los animales de cresta en nuez y el color del tarso amarillo fue el más sobresaliente y el blanco no tuvo ninguna significación. 


\section{VALDÉS CORRALES, PIMENTEL, MARTÍNEZY FERRO}

Entre los colores del pico, el amarillo es el que más significación presenta. En el resto de los rasgos no se realizó comparación entre los valores por presentar sólo dos caracteres cada uno.

\section{CONCLUSIONES}

La apariencia fenotípica de algunos ejemplares muestreados corresponde a estirpes

\section{BIBLIOGRAFÍA}

Espinosa, R. 1991. Caracterización morfológica de la gallina mestiza de Chiapas. Tesis de licenciatura. Universidad Autónoma de Chiapas. Chiapas.

Goudja, A. 1994. Características morfológicas y productivas de la raza local Seckné. Sistema de Información para la Diversidad de los Animales Domésticos. FAO. http://dad.fao.org/cgi-dad/ \$cgi_dad.dll/databases?eng (22/03/2001). comerciales, lo que sugiere el grado de penetración de aves de razas exóticas introducidas, a la población de gallinas criollas del área. Las gallinas de cresta simple y emplume normal muestran frecuencia superior a los demás rasgos, a pesar de que en ambos casos se trata de genes recesivos debido a una mayor capacidad de adaptación a las condiciones climáticas.

Kirby, J.D., Tressler, C.J. and Kirby, Y. 1998 Evaluation of the duration of sperm fertilizing ability in five lines of commercial Cuban broiler breeder and Delaware cross males. Poultry Sci., 77: 1688-1694.

Pérez, M. 1993. Valoración de una nueva raza de aves semirústicas en Cuba. Tesis en opción al grado de Dr. en Ciencias Veterinarias. Universidad Agraria de La Habana. La Habana. 246 pp. 